\title{
Impact of Climate Change on Water Resources Management in the Lower Chao Phraya Basin, Thailand
}

\author{
Sanit Wongsa \\ Department of Civil Technology Education, King Mongkut's University of Technology Thonburi (KMUTT), \\ Bangkok, Thailand \\ Email: sanit.won@kmutt.ac.th
}

Received November 2015

\begin{abstract}
Climate change and associated rising in sea water level have affected the salinity in many rivers around the world. It has an effect on the embouchure adjacent with the sea, which is called the salinity intrusion problem. This study investigated the effects of climate change on sea water level that affects the hydraulic conditions, salinity, water supply and agricultural areas in the lower Chao Phraya River by MIKE 11 model has been used. The study covered the area from Chao Phraya Dam (barrage), Chai Nat Province to the river estuary, Samut Prakan Province. The model was divided into two parts, hydrodynamic module and advection-dispersion model. Calibration of each part was done by adjusting its important coefficients. It was observed that the Manning's coefficient $(\mathrm{n})$ and coefficient dispersion of mass were in the range of $0.025-0.40$ and $800-1600 \mathrm{~m}^{2} / \mathrm{s}$, respectively. The results of comparison between models and observation data revealed order of forecasting error $\left(R^{2}\right)$ with the range of $0.76-0.99$ for water level and $0.73-0.86$ for salinity. The RCP 8.5 scenario from IPCC report was simulated. It was found that sea water level rising in was $1.16 \mathrm{~m}$ in the year of 2100, and salinity at SamlaePump Station was risen to $0.37-0.75 \mathrm{~g} / \mathrm{l}$. The value of $0.25 \mathrm{~g} / \mathrm{l}$ exceeding standard and the pointed tip of salinity was at Koh Rain District, Ayutthaya Province (137 km from Chao Phraya Dam: CPD). For agricultural sectors, the value of 0.20 $\mathrm{g} / \mathrm{l}$ exceeding standard and the pointed tip of salinity was at Ban Mai District, Ayutthaya Province (123 km from CPD). Results obtained from this study will give the guideline in raw water resources management for water supply and agricultural in Chao Phraya River Basin.
\end{abstract}

\section{Keywords}

Climate Change, Water Resources Management, Lower Chao Phraya River, Salinity Intrusion

\section{Introduction}

Climate change has been observed having local and global effects. Most of the effects were negative. The notable phenomena effected by extreme weather events, are heavy rains, heat waves, and draught. Climate change causes serious risks to the well-being of nature and people all over the world. Within the estuaries, sea water can 
be the important controls of water level, salinity and coastal erosion. Although the precise effect of climate change on estuaries dynamics and its processes in the alluvial river system is still not clear, there seems to be no doubt that it influences sea water level and salinity intrusion. Recently, numerical modelling has been shown to answer some of these problems. A number of works have used numerical models attempting to simulate river catchment hydrological processes of rainfall-runoff, sediment transport, salinity intrusion and coastal erosion processes as well as to study the impact of climate change. In addition, the numerical model has been applied to predict hill slopes and river channels [1]-[5]. Thus, it is clear that the numerical models appear to have considerable potential as tools for investigating hydrodynamic, sediment transport and water quality over long period simulation. [6] have predicted that sea water level affected rice production in Mekong Delta, Vietnam, during the flood season. However, there are a few application studies in Thailand. [7]-[10] have exploited MIKE11 model to predict sea level affecting salinity intrusion and agricultural production in Tha Chin, Mae Klong and Chao Phraya rivers. Metropolitan Waterworks Authority (MWA) reported that salinity intrusion and raw water supply in Chao Phraya River was affected by climate change.

This paper addresses these issues by using a pro-posed MIKE11 numerical modelling to simulate the effects on sea water level change and salinity intrusion. Performance of the numerical model was applied to simulate flow events in 2100, which are water level change and salinity intrusion on raw water supply in the Lower Chao Phraya River, Thailand.

\section{Material and Methods}

\subsection{Study Area}

Chao Phraya River is the most important and largest river flowing from Chai Nat Province to estuary at the Gulf of Thailand in SamutPrakan Province, located at central part of Thailand. The climate of the Chao Phraya River has a tropical wet and dry or savanna climate, which generates wet and dry seasons of more or less equal length. The monsoon season is usually from May until late September and/or early October. In the wet season, averagely 1 - 2 tropical depressions occur over much of the area from August to October of the year. The average annual discharge is $718 \mathrm{~m}^{3} / \mathrm{s}$ and rainfall varied between 1122 to $1511 \mathrm{~mm}$, depending on monsoon direction and elevation. However, some parts of the catchment continue to suffer from drought problems due to the uneven distribution of rainfall. Some areas experience both flooding and drought conditions in a single year, due to temporal and spatial uncertainties in the monthly rainfall and/or the poor management of the conveyance infrastructure. The common practice in Thailand is to manage the risks after considering which areas are likely to be vulnerable to either flood or drought. Failure to manage risk by addressing one aspect at a time can lead to adverse results. Therefore, climate change and an association with managing flood and drought risks are new challenge in Thailand and becoming increasingly important.

\subsection{MIKE11 Model}

The MIKE11 model has been used. This numerical model simulates water flow and salinity as a consequence of low flow conditions. The shallow water equation was used for simulation of 1-D unsteady water flow and transportation of mass was used for salinity. To modelling the river network of the Lower Chao Phraya, a digital elevation map (DEM) was applied. The model input data were cross-section, flow discharge, water level, side flow and salinity. The MIKE11 program, 6-points Abbott's finite difference scheme was used to solve governing equations, consisting of separate modules each representing a different procedure in calculation process. A first module calculated hydrodynamics of river flow (HD module), and the next module of transportation of mass (salinity intrusion; AD module). The model setup of plan view and longitudinal profile of the Lower Chao Phraya are shown in Figure 1.

\section{Results and Discussion}

The Lower Chao Phraya River was used for calibration and verification of the proposed model. The calibration and validation has focused on the applicability of water flow and salinity intrusion by using flow conditions in the year of 2008 and 2010. Performance of the foregoing numerical model was applied to simulate scenario of IPCC SRES (RCP8.5), predicted from global average sea level rising from 1990 to 2100 by using GCMs. RCP8.5 scenario is a scenario of comparatively high greenhouse gas emissions [11]. For model simulation, flow 

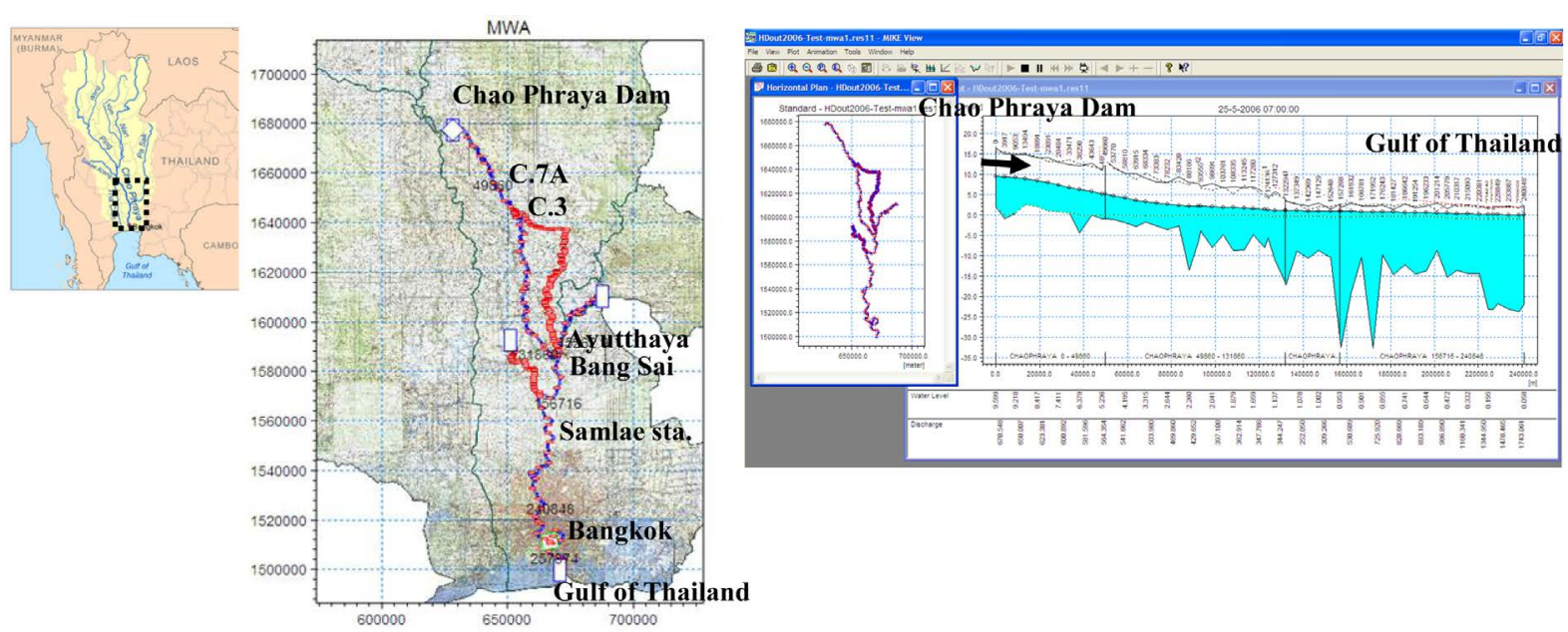

Figure 1. Study area of the Lower Chao Phraya River and model setup.

discharge at station C.13 (Chao Phraya Dam: CPD) and water level at Chao Phraya River Estuary (Fort Chula) were adopted for upstream and downstream boundaries, respectively. Before the water flow and salinity calculation was carried out, the model was run to provide the steady state of necessary flow variables.

\subsection{Model Calibration and Verification}

The comparison of time series of measured and simulated water surface level and salinity at two major gauge stations and Manning's roughness coefficient (n) are shown in Figure 2 and Figure 3. Good agreement between the simulated and measured hydrographs for the low flow events was achieved by considering side flow and pumps in the areas. The coefficient of determinant $\left(\mathrm{R}^{2}\right)$ and Index of agreement (IA) have been used as the main criteria to judge whether the data fitted between measurement and simulation. The comparison model was followed by adjusting important coefficient of two parts. The results of manning (n), global dispersion factor, global exponent and $\mathrm{K}_{\text {mix }}$ were in the range of $0.022,500-1800 \mathrm{~m}^{2} / \mathrm{s}, 0.1-0.8$ and $500-1800 \mathrm{hr}^{-1}$, respectively. The results of comparison between models and observation data revealed the order of forecasting error, $\mathrm{R}^{2}$ and IA in the range of $0.88-0.91,0.94-0.97$ for water level and $0.86-0.96,0.75-0.94$ for salinity. These indicate well fitted between measured data and this proposed model. Good agreement between the simulated and measured water surface level was achieved by considering side flow and pumps in the areas for model verification. It was observed that the values of $\mathrm{R}^{2}$ and IA for two major gauge stations in verification period were between 0.93 0.94, 0.97 - 0.98 for water level and 0.71 - 0.91, 0.72 - 0.87 for salinity, indicating well fitted between measured data and this proposed model (Figure 4 and Figure 5). Good performance of simulated results was observed in both water flow and salinity intrusion characteristics, therefore, indicating that model simulation is reasonable.

\subsection{Model Application}

For model application, a scenario RCP8.5 from IPCC report was simulated. The comparison of time series of measured and simulated flow discharge at the major gauge stations are shown in Figure 6 and Figure 7. It was found that sea water level at the Chao Phraya estuary had rising and betaking tendency to intrusion of sea water level. Salinity was shown to be in the same tendency. For IPCC SRES in the year of 2100, sea water level rising in RCP8.5 scenario was $1.16 \mathrm{~m}$, and salinity values and intrusion distant were in the range of $0.38-0.45 \mathrm{~g} / \mathrm{l}$ and 142.0 - $157.0 \mathrm{~km}$ (from Chao Phraya Dam), and salinity at Samlae Station were $0.29-0.37 \mathrm{~g} / \mathrm{l}$. The value of $0.25 \mathrm{~g} / \mathrm{l}$ exceeding standard and the pointed tip of salinity was at Bang Sai District, Ayutthaya Province. The worst case scenario, a constant value of salinity of $30 \mathrm{~g} / \mathrm{l}$ was adopted at the Gulf of Thailand. It was found that salinity at Samlae Station was $0.99-1.70 \mathrm{~g} / \mathrm{l}$, the value of $0.25 \mathrm{~g} / \mathrm{l}$ was at Pratuchai Sub-district, Ayutthaya Province, $133.0 \mathrm{~km}$ from Chao Phraya Dam. We could also observe from the simulation that the climate change would have more conspicuous effects in rising up sea water. However, Metropolitan Waterworks Authority reported that climate change affected salinity intrusion and raw water supply in Lower Chao Phraya River. This observation demonstrated that Samlae Pumping Station will not be available when salinity is over 0.25 and/or 


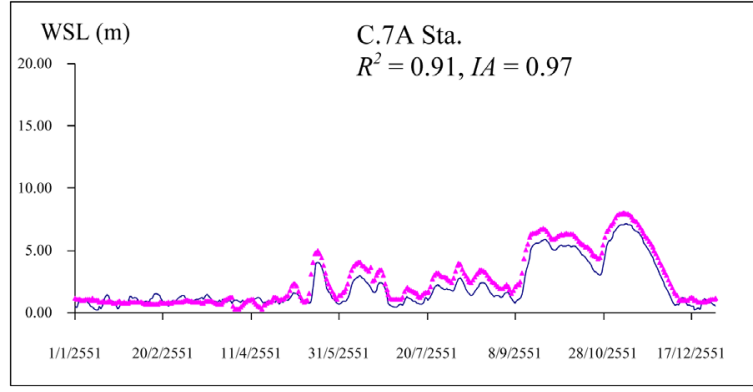

Time $\rightarrow$

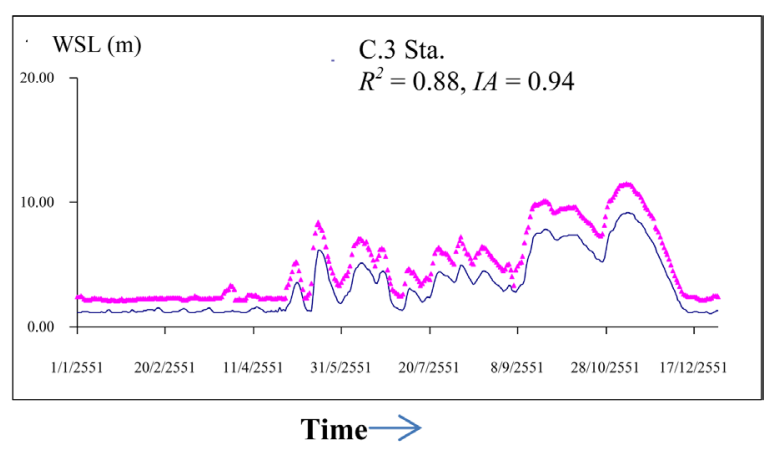

Time $\longrightarrow$

Figure 2. Comparison of time series of stage hydrograph between simulated results (smoothed-line) and measured data (dotted) at the major gauge stations (model calibration).

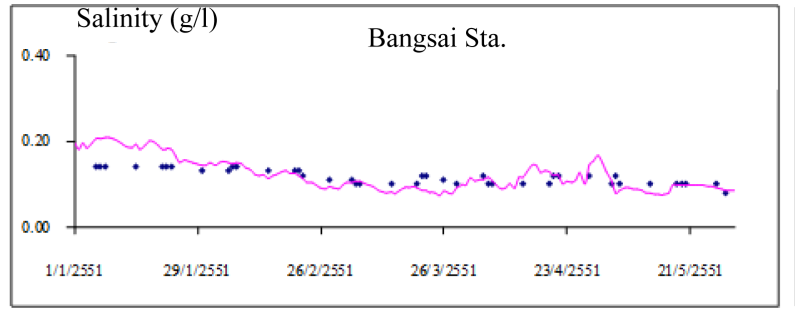

Time $\rightarrow$

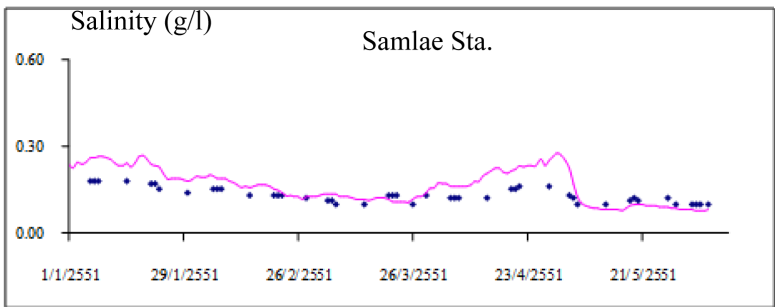

Time $\rightarrow$

Figure 3. Comparison of time series of salinity between simulated results (smoothed-line) and measured data (dotted) at the major gauge stations (model calibration).

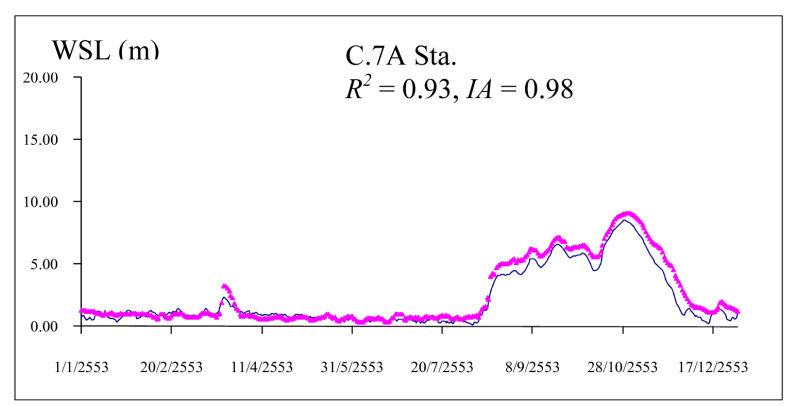

Time $\rightarrow$

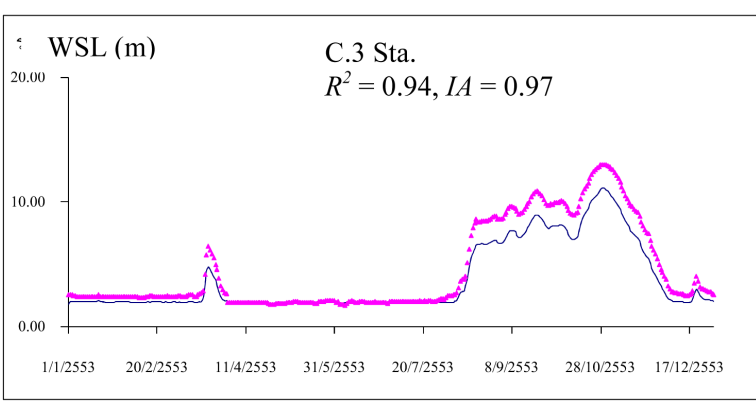

Time $\rightarrow$

Figure 4. Comparison of time series of stage hydrograph between simulated results (smoothed-line) and measured data (dotted) at the major gauge stations (model verification).

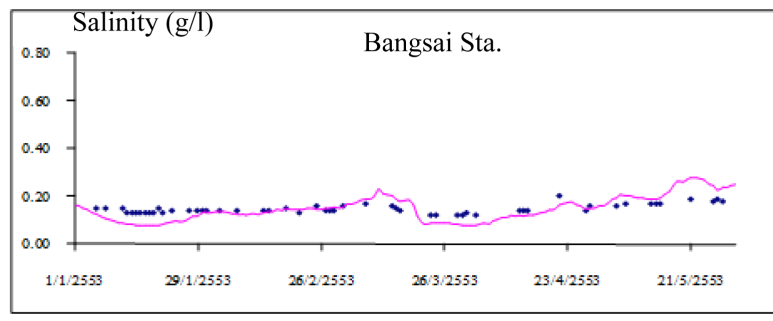

Time $\rightarrow$

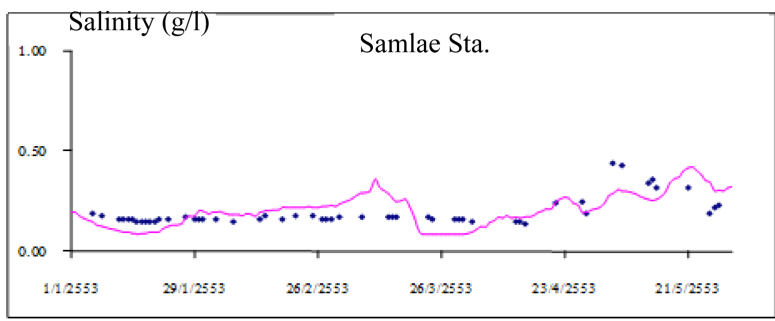

Time $\rightarrow$

Figure 5. Comparison of time series of salinity between simulated results (smoothed-line) and measured data (dotted) at the major gauge stations (model verification). 


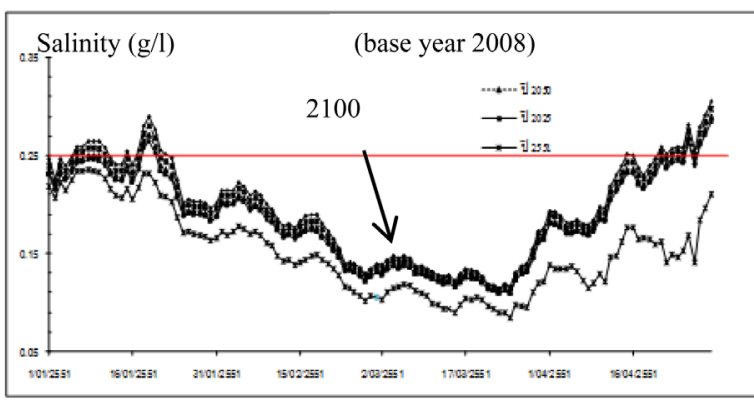

Time $\rightarrow$

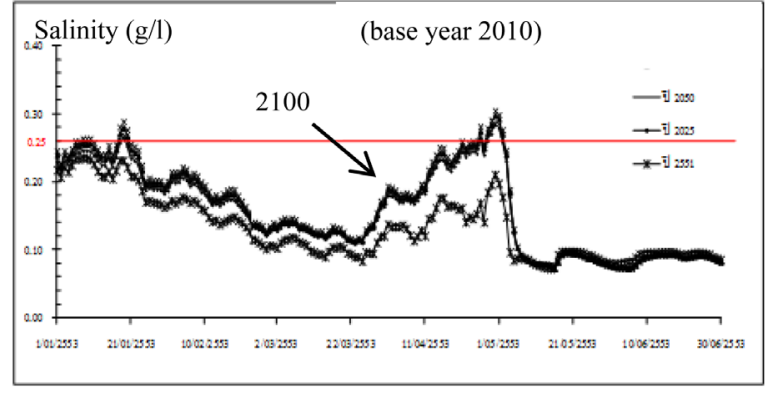

Time $\rightarrow$

Figure 6. Salinity in the year of 2100 (IPCC), with $1.16 \mathrm{~m}$ sea water level rising in RCP8.5 scenario (model application).

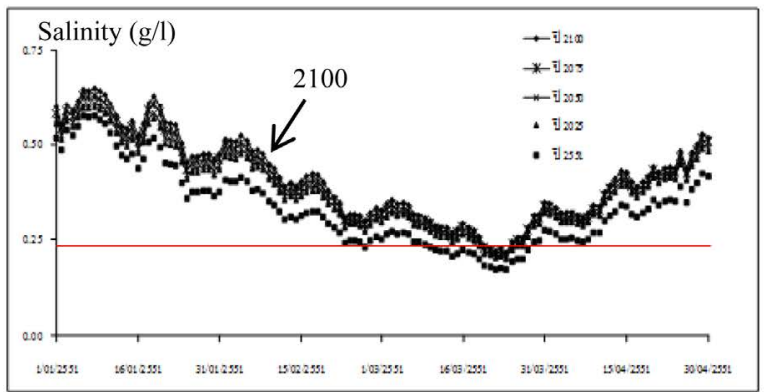

Time $\longrightarrow$

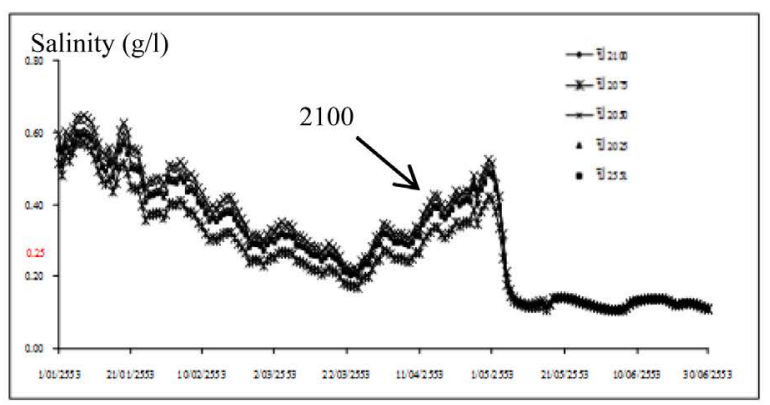

Time $\rightarrow$

Figure 7. Salinity in the year of 2100 (IPCC), with $1.16 \mathrm{~m}$ sea water level rising in RCP8.5 scenario and salinity $30 \mathrm{~g} / \mathrm{l}$ at downstream (model application).

$0.50 \mathrm{~g} / \mathrm{l}$, and water supply shortage. The mitigation plan has suggested the diversion flow from Mae Klong River and construction of new pump station for short-term and long-term, respectively. The proposed locations of new raw water pump station along the Chao Phraya River from Ayutthaya to Singburi Province have been investigated. It was found that the most suitable sites when evaluation by multi-criteria analysis (MCA) is at KlongPongpheng, Ayutthaya Province (site 4).

Water level change will affected the water supply in urban, and agricultural areas. Salinity level less than 0.2 g/l was not impacted; it can use irrigation for any planting. Salinity level from 0.2 had little impact, while salinity level from 0.5, and salinity level more than $1.5 \mathrm{~g} / \mathrm{l}$ were highly impacted (Figure 8). For agricultural sectors, the value of $0.20 \mathrm{~g} / \mathrm{l}$ exceeding standard and the pointed tip of salinity was at Ban Mai District, Ayutthaya Province (123 km from Chao Phraya Dam).

\section{Conclusion}

In this study, the MIKE11 model was exploited to simulate the effects of climate and sea level changes on the raw water supply of MWA and agricultural areas in the lower part of Chao Phraya River in the year 2100. The study covered the area from Chao Phraya Dam, Chai Nat Province to the Gulf of Thailand at Samut Prakan Province. IPCC SRES predicted that in the year 2100, sea water level rising in RCP8.5 scenario was $1.16 \mathrm{~m}$. Based on this information, the simulation showed that salinity at Samlae will be exceeded $0.25 \mathrm{~g} / \mathrm{l}$. Therefore, it is suggested to add pump station at Samlae to site (4) at KlongPongpheng, borderline of Ayutthaya and Ang Thong Province. This will help to balance level of salinity in river not over $0.25 \mathrm{~g} / \mathrm{l}$. For agricultural sectors, the value of $0.20 \mathrm{~g} / \mathrm{l}$ exceeding standard and the pointed tip of salinity was at Ban Mai District, Ayutthaya Province (123 km from Chao Phraya Dam). Results obtained from this study will give guideline in raw water resources management for water supply and agricultural in Chao Phraya River Basin.

\section{Acknowledgements}

The authors would like to thank NRU-National Research University and King Mongkut’s University of Tech- 

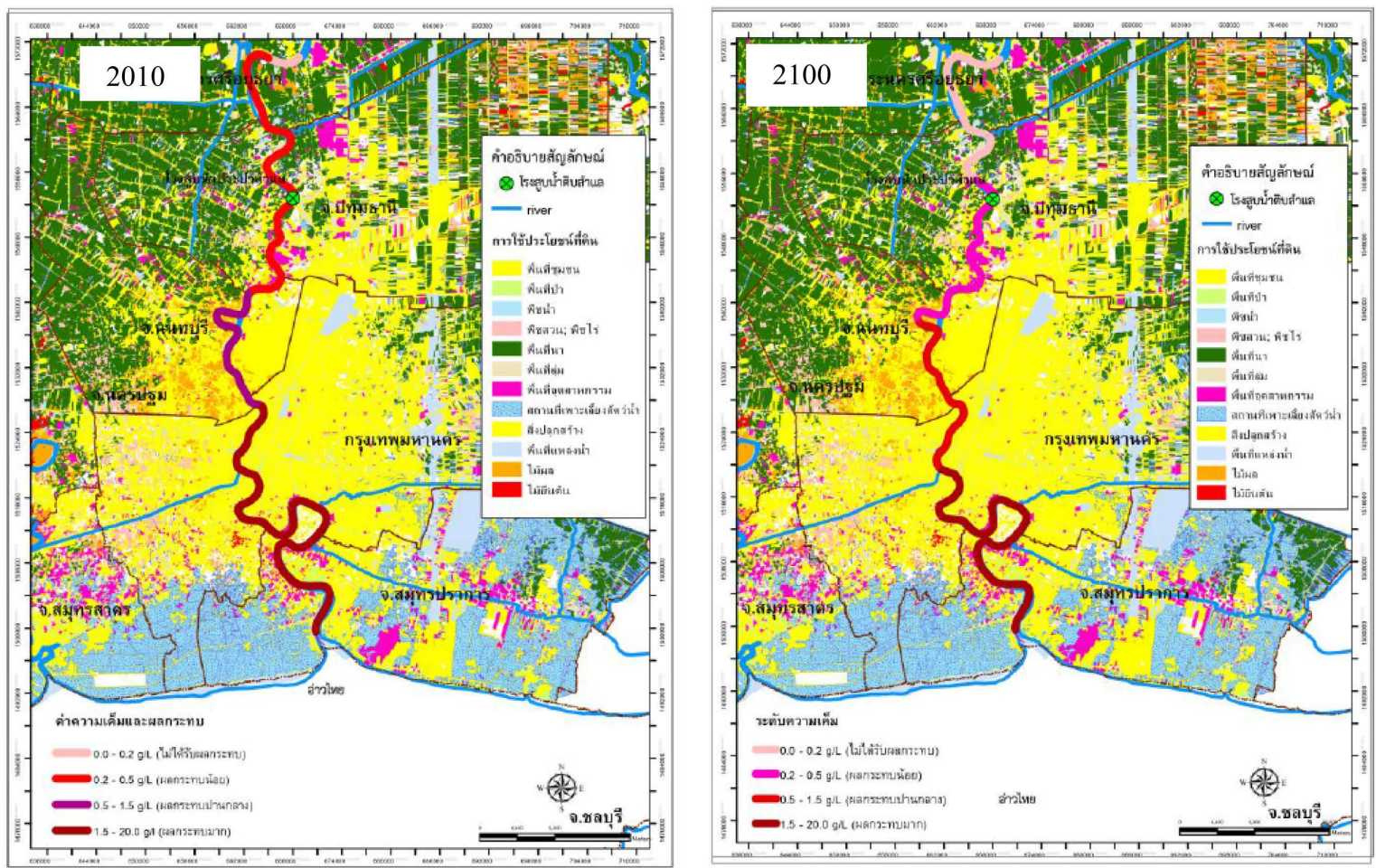

Figure 8. Salinity profile in the year of 2010 and 2100 (IPCC SRES).

nology Thonburi (KMUTT). We are also indebted to Metropolitan Waterworks Authority (MWA), Royal Irrigation Department (RID) and Pollution Control Department (PCD) for providing fields data.

\section{References}

[1] Kirby, M.J. (1987) Modelling Some Influences of Soil Erosion, Landslides and Valley Gradient on Drainage Density and Hollow Development. Catena Supplement, 10, 1-11.

[2] Wicks, J.M. and Bathurst, J.C. (1996) SHESED: A Physical Based, Distributed Erosion and Sediment Yield Component for the SHE Hydrological Modelling System. Journal of Hydrology, 175, 213-238. http://dx.doi.org/10.1016/S0022-1694(96)80012-6

[3] DHI Water and Environment (2000) MIKE11: A Modeling Sys-Tem for Rivers and Channels_User Guide, Denmark.

[4] Wongsa, S. and Shimizu, Y. (2004) Modelling Artificial Channel and Landuse Changes and Their Impact on Floods and Sediment Yield to the Ishikari Basin. Hydrological Processes, 18, 1837-1852. http://dx.doi.org/10.1002/hyp.1450

[5] Wongsa, S. (2004) Distributed Model for Catchment Scale Simulation of Runoff and Sediment Transport. Ph.D. Thesis, Hokkaido University, Japan.

[6] Wassmann, R., Hein, N.X., Hoanh, C.T. and Tuong, T.P. (2004) Sea Level Affecting Vietnamese Mekong Delta: Water Elevation in the Flood Season and Implications for Rice Production. Climate Change, 66, 89-107. http://dx.doi.org/10.1023/B:CLIM.0000043144.69736.b7

[7] Wongsa, S. and Ekkawatapanit, C. (2009) Effect of Sea Water Level Change on the Management in the Lower Thachin River. Report for ESS Program, King Mongkut's University of Technology, Thonburi, Thailand.

[8] Wongsa, S., Ekkawatapanit, C. and Treerittiwitaya, K. (2010) Effect of Sea Water Level Change on the Management in the Lower Thachin River. Proceedings of the International Symposium on Coastal Zones and Climate Change: Assessing the Impacts and Developing Adaptation Strategies, Australia.

[9] Wongsa, S., Kamolsin, P. and Inkliang, K. (2010) Effect of Sea Water Level Change on the Estuaries Management in the Lower Thachin and Mae Klong Rivers. Proceedings of GMSTEC 2010: International Conference for a Sustainable Greater Mekong Subregion, Bangkok, Thailand.

[10] Sueathung, S. and Wongsa, S. (2015) Effect of Sea Water Level Change on the Water Resources Management and Agriculture in Chao Phraya River. Proceedings of NCCE2015, Chonburi, Thailand.

[11] http://www.ipcc.ch/ 